governed with diverse and contesting ways of understanding, filled with contradictions, categorization, labelling and marginalisation. Hence, these ways of knowing problematizes TLA and its pupils in a normative ways. It situates them outside the 'normal' 'Anga FakaTonga' (Tongan ways) mainly because their distinctive behaviours are perceived as falling outside the 'Anga FakaTonga' awareness of acceptable behaviour and attitude. It is, therefore, position Leitis as 'children of the devil'. The TLA and its pupils are variously described as being at-risk, vulnerable, stigmatised and lacking agency.

Results Moreover, their lives are equated with having a 'lack of hope and mobility' so they are seen as being on a pathway that leads to 'poverty' and isolation from normative model and space in Tongan society. We recognised that through positioning outside the 'normal Anga FakaTonga', there is a tendency to perceive TLA and its pupils in a simplistic way and thus treat them as a marginal community.

Conclusion However, it must be acknowledged that this tendency to stereotype TLA and its pupils displays a lack of awareness for their:

- active agency and the fact they have some control over their life journey,

- contributions to Tongan civil society,

- distinctive cultural, gifts and artistic talents,

- support to the business communities,

- capacity to support the younger Leiti's pupils,

- capacity to educate the general public regarding the sexually transmitted diseases - HIV/AIDS and STI's, and

- Marketing of Tonga to the international communities.

Disclosure of interest statement The Tonga Leiti's Association (TLA) is a Registered Association in the Kingdom of Tonga. The TLA works as an advocacy organisation focused on the promotion of the rights and creating a dialogue about issues facing the transgendered community in Tonga. The TLA aims to oversee any opportunities addressing human rights and also to carry out awareness to its members. As a Registered Association of Tonga the TLA is required to have board members which include representatives from the government and non-government organisations. The TLA is a voluntary organisation and all of the staff are volunteers. I am the current Executive Director of the TLA and the current Chairperson of the Pacific Sexual Diversity Network. The Hon. Lupepau'u Tuita from the Tongan Royal Family is the Patron of the TLA. At the Annual General Meeting there are appointed positions that are tasked with the administration and operating of the Association.

\section{P14.16 SELF REPORTED HIV DISCRIMINATION AND WILLINGNESS TO DISCLOSE HIV SEROPOSITIVITY AMONG A SAMPLE OF TURKS AND CAICOS ISLANDERS}

${ }^{1}$ A Robinson*, ${ }^{2}$ SD Malcolm. 'National AIDS Program, Ministry of Health, Grand Turk, Turks and Caicos; ${ }^{2}$ National Epidemiology and Research Unit, Ministry of Health, Grand Turk, Turks and Caicos

\subsection{6/sextrans-2015-052270.528}

Background Human Immunodeficiency Syndrome (HIV) is a major source of concern in the Turks and Caicos Islands (TCI), a small archipelago of islands in the Caribbean region. Since transmission is predominantly through sexual contact, it is important to understand the dynamics of sexual relationships in this country, including the likelihood of HIV seropositivity disclosure. Knowledge about one's partner's seropositivity can guide both the sexual behaviour and HIV testing decision-making processes. The objective of the study was thus to examine factors associated with willingness to disclose HIV status in a general TCI sample, including self-reported discrimination towards HIV positive persons, which has rarely been examined in relation to disclosure.

Methods The current study is based on secondary analysis of the 2011 Knowledge, Attitudes Practices and Behaviours survey data $(\mathrm{N}=837 ; 55 \%$ female; mean age $=31.28(\mathrm{STD}=9.3))$. Multivariate logistic regression examined the association between willingness to disclose HIV seropositivity to partner (Yes/No) and gender, age, sexual partner number, church attendance, cohabitation status, HIV treatment knowledge, ever tested status and self-reported HIV discrimination.

Results Nearly half of the participants were unwilling to disclose HIV seropositivity (44.8\%). Moreover, willingness to disclose HIV seropositivity was related to having one or less sexual partner $(\mathrm{OR}=1.98,95 \% \mathrm{CI}=1.29-3.01)$, non-regular church attendance $(\mathrm{OR}=1.55,95 \% \mathrm{CI}=1.10-2.19)$, cohabitation $(\mathrm{OR}=0.67,95 \% \mathrm{CI}=0.47-0.97)$, knowing about HIV treatment $(\mathrm{OR}=0.50,95 \% \mathrm{CI}=0.32-0.80)$ and having an HIV test $(\mathrm{OR}=0.43,95 \% \mathrm{CI}=0.26-0.63)$. Self-reported discrimination was also related to willingness to disclose HIV seropositivity $(\mathrm{OR}=0.62,95 \% \mathrm{CI}=0.44-0.88)$.

Conclusion Several factors were associated with willingness to disclose HIV seropositivity, including self-reported discrimination. These findings may have implications on post HIV test counselling initiatives, which should include a focus on education.

Disclosure of interest statement Nothing to declare.

\section{P14.17 SURVEILLANCE FOR SEXUALLY TRANSMITTED INFECTIONS AMONG FEMALE SEX WORKERS IN INNER- CITY JOHANNESBURG}

${ }^{1}$ V Black, ${ }^{2}$ V Maseko, ${ }^{1} F W$ Venter, ${ }^{2} F$ Radebe, ${ }^{1} S$ Mullick, ${ }^{1} H V$ Rees, ${ }^{2,3}$ DA Lewis. ${ }^{1}$ Wits Reproductive Health and HIV Institute, Faculty of Health Sciences, University of Witwatersrand; ${ }^{2}$ Centre for HIV and STIS, National Institute for Communicable Diseases (NHLS); ${ }^{3}$ Western Sydney Sexual Health Centre and University of Sydney, Sydney, Australia

\subsection{6/sextrans-2015-052270.529}

Introduction Sexually transmitted infection (STI) surveillance informs empiric antibiotic recommendations for syndromic management. Asymptomatic STIs are an important source of new infections which increase the risk of HIV transmission and acquisition. As female sex-workers (FSW) are key HIV/STI transmitters, microbiological studies within this population provide critical HIV/STI strategic information.

Methods Female sex workers (FSW) attending a sex-worker clinic or outreach brothel services, between March and December 2014 in inner-city Johannesburg were enrolled. A questionnaire and clinical examination were completed. Specimens were collected from the throat, urethra, cervix, vagina and rectum. Laboratory investigations included (i) culture for Neisseria gonorrhoeae (NG) with susceptibility testing for cefixime and ceftriaxone, (ii) DNA amplification using a multiplex PCR for NG, C. trachomatis (CT), M. genitalium (MG) and T. vaginalis (TV), (iii) microscopic examination for bacterial vaginosis (BV), and (iv) serological testing for syphilis, hepatitis B and HIV. Participants with STIs were treated either at the initial visit (symptomatics) or following recall (asymptomatics).

Results The mean age of the 268 enrolled FSW was 31.5(IQR $27-35$ ) and mean duration of sex work was 4.9 years (range 2 months-30 years). Condom use was consistent among 88 